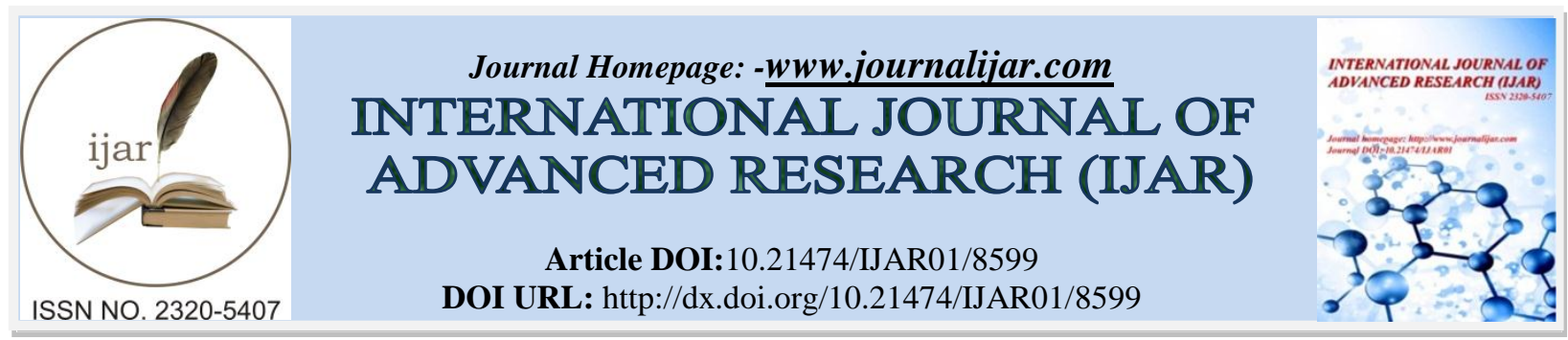

RESEARCH ARTICLE

\title{
ISOLATION AND IDENTIFICATION OF BACTERIAL CONTENT IN BLOOD BANK REFRIGERATORS.
}

Rasha Kifah Hassan, Ahmed Ibrahim Jessim, Ammar Salim Salman and Abbas Fadhil Salman. Ministry of Science and Technology, Treatment and disposing of chemical, biological and military hazardous wastes, Center for research and development, Baghdad - Iraq.

\section{Manuscript Info}

Manuscript History

Received: 02 January 2018

Final Accepted: 04 February 2019

Published: March 2019

Keywords:-

Blood bank refrigerators,

Staphylococcus aureus, Bacillus cereus, and Enterococcus faecalis.

\begin{abstract}
The aim of this study is to isolate and identify

Species of blood-contaminated bacteria in Blood bank refrigerators which they are out of service for several reasons can be diagnosis and identification via Five samples (Swabs) which they are prepared from inside of lefted refrigerator at the stores of the private nursing hospital at the city of Baghdad, samples are cultured on blood agar media, after 24 hours, results showed three species of bacteria, these bacteria are diagnosed via biochemical and enzyme-based tests according to Bergey's Manual 2005, which they are Staphylococcus aureus, Bacillus cereus, and Enterococcus faecalis. These species are diagnosed because of their ability to resist environmental conditions for a long time. There are other species of bacteria are not being diagnosed because of inability to resist dryness or changing of temperature degrees or sterilization.
\end{abstract}

Copy Right, IJAR, 2019,. All rights reserved.

\section{Introduction:-}

The first attempts on blood transfusions have been initiated and reported into the 19th century by James Blundell, where he did the first human blood transfusion between veins and that was successful in postpartum hemorrhage cases. At 1916, the first blood transfusion was performed using the blood that was stored and cooled by Oswald Hope Robertson, who was credited with establishing the first blood bank in France during the First World War, where the urgent need for heavily transfused blood into the wounded soldiers. During the Second World War, about 13,000 blood units were donated In United States. In London, more than $260000 \mathrm{~L}$ was collected and distributed. Without a doubt, blood transfusion carried with it urgent need to preserve blood by adding anticoagulants and cooling it between $\left(2-6{ }^{\circ} \mathrm{C}\right)$ to keep it from decomposition and change its constituents (Carson et al., 2016). Here appeared the need for blood bank refrigerators as a store for storing blood and its constituents, collected from donators, where blood is collected and stored for later use of blood transfusion operations (Ibrahim, 2013). Blood bank refrigerators are very important to all hospitals, clinics and blood banks for the urgent need to save blood bags or blood constituents such as plasma and platelets when needed (Masalha et al., 2001). There are a number of conditions must be taken into consideration in the preservation of blood, including that after withdrawing blood from the donator, blood must transfer immediately to the refrigerator under a controlled temperature which must be between $2-6{ }^{\circ} \mathrm{C}$. If temperature of refrigerators are more than $6{ }^{\circ} \mathrm{C}$ occurred break blood cells and activate Bacteria and if the temperature less than $2{ }^{\circ} \mathrm{C}$, the blood will freeze, In addition to maintaining a sterile atmosphere during all 
stages of blood withdrawal and make sure blood tests before putting it in the refrigerator varies preservation temperature according to the type of blood component, the keeps whole blood in refrigerators of temperature from 2 to $6{ }^{\circ} \mathrm{C}$. Fresh plasma is kept in the refrigerators temperature range from $2-6^{\circ} \mathrm{C}$ for 12 hours or froze from $(-40$ to $80^{\circ} \mathrm{C}$ ), while platelets Bloody reservation at room temperature from 72 to 96 hours only (Ibrahim, 2013; Masalha et al., 2001). As blood is an ideal environment of the growth for many pathogenic microorganisms that cause serious diseases such as sepsis, Myocarditis, Arthritis, skin infections, Urinary tract infection, abortion and fever types (Tong, 2015). So make sure the safety of refrigerators to keep blood from pollution for a long time (MOH, 2013). This study aims to isolate and diagnose bacterial content in blood storage refrigerators. The aim of this study is to diagnose and identify species of blood-contaminated bacteria in Blood bank refrigerators which they are out of service for several reasons

\section{Materials and Method:-}

The private nursing home hospital was equipped with blood-bank( refrigerators), an ELT type of UK origin that had been operating since the establishment of the private nursing home hospital in the seventies of the last century, then they were taken out of service at 2003, and they are used as a cupboard to store detergents. An exterior appearance of the blood bank refrigerators consists with metal gate insulated with thermal insulation, locked and equipped with a glass door at the middle of it, inner compartment of refrigerators contains easy-to-slip mesh shelves to facilitate the sampling function. Refrigerators interface has a small digital display to show the set temperature of the fridge. Swabs have been taken from (22) unemployed refrigerators in order to identify the types of an obtained pollution

\section{Sampling}

Samples are collected from 22 refrigerators in the form of a cotton swab. They were taken directly to the laboratory for isolation and diagnosis, all samples were taken periodically for five times.

\section{Culture media}

1. Samples are Cultivated on Nutrient agar media, later incubated at $37{ }^{\circ} \mathrm{C}$ in aerobic condition incubator for 24 hours.

2. Isolation of each bacterial type obtained separately from cultured colonies on Nutrient agar media and cultured after purification in small Vial sealed tubes in a slant manner.

3. Samples of the colony (in the loop) are taken from isolated colonies then stained with gram stain to examine bacterial type, shape, size, and cell wall interaction with stain.

4. Colony samples are taken and stained with spore stain to determine the number, shape, and location of spores in the cell body.

5. Via blood agar, haemolysis test is performed by adding $5 \mathrm{ml}$ of blood to the medium, mixed well and leave for solidification, later injected with bacteria.

6. Coagulase test is performed by growing bacteria on $0.5 \mathrm{~mL}$ of plasma after incubating at $37^{\circ} \mathrm{C}$ along 24 hours.

7. to determine the ability of the bacteria to analyze $\mathrm{H}_{2} \mathrm{O}_{2}$ or not, Catalase test is performed when a drop of hydrogen peroxide placed on a colony above the glass slide and observe the formation of bubbles.

8. glucose analysis test is performed where glucose adding on Neutral broth media Methyl red detector with overturned Durham tube and bacterial culture, then incubate at $37{ }^{\circ} \mathrm{C}$ along 24 hours

9. dimensions of bacteria are measured via digital optical microscope connected with a digital screen.

10. With the test of Voges Proskauer via using Buffer Glucose broth where bacteria cultured and incubated at $37{ }^{\circ} \mathrm{C}$ for $48 \mathrm{~h}$ after using $1 \mathrm{ml}$ of alpha-naphthol $\mathrm{C}_{10} \mathrm{H}_{7} \mathrm{OH}$ And $3 \mathrm{ml}$ of $\mathrm{KOH}$ potassium hydroxide and left for 10 minutes.

11. Bacterial growth examined in a medium which contains $6.5 \%$ of $\mathrm{NaCl}$, were added to the Neutral Agar and incubated at $37^{\circ} \mathrm{C}$ for 24 hours

12. To perform amylase test, bacteria were cultured in center of $10 \mathrm{~g}$ of potato starch, $5 \mathrm{~g}$ of pancreatic gelatin digest, $3 \mathrm{~g}$ from beef extract, $15 \mathrm{~g}$ of agar per liter in distilled water, $\mathrm{pH}$ adjusted to 6.8, after that Iodine added to observe areas surrounding growth, then mixture incubated at $25{ }^{\circ} \mathrm{C}$ till appearance of areas surrounding growth

13. For mannitol test for Staphylococcus aureus, Mannitol Salt Agar medium from the Dutch company Salucea as a selective medium used by preparing mannitol media agar from dissolving 111g of Mannitol Salt Agar in one litter of Distilled water, with adjustment $\mathrm{pH}$ of the solution to 7.4 at $25^{\circ} \mathrm{C}$.

14. To test mortality of bacteria, Hanging Drop Method used via using glass slides (glass slide with dropping) with put a lid containing a drop of nutritious broth in the middle and paste with water droplets on the corners of the cover (Wade Road, 1982). 


\section{Results:-}

After morphological and biochemical tests, results showed the bacterial content was mainly composed of three species which they are Staphylococcus sp., S. aureus, Bacillus sp., B. cereus, and Enterococcus sp., E. faecalis with other individuals belonging to same families are not identified as species (Billström et al., 2008).

\section{Staphylococcus aureus}

After gram stain, results of the microscopic examination showed that the bacteria were examined as cocci with a diameter of $1 \mu \mathrm{m}$ (Senok et al., 2009) staphylococci, and G + and appeared on the Neureint agar in relatively large colonies diameter 2-4 mm yellow gold smooth and convex, and do not form spores when they are tested. Also, the result was positive for catalase test, and fermentation of glucose, starch and Voges Proskauer. To detect pathogenesis of S.aureuscoagulation plasma is tested and gave positive results. In addition to that, when the cultivation on the center of Blood agar analyzed blood type of B-Hymatolysis colonies are grew and surrounded with aura transparent, and when cultivated on broth nutrient containing the sodium salt, grown significantly and has grown well on the Mannitol Salt Agar diagnostic agent for $S$. aureus. The medium color is changed from red to yellow, indicating the fermentation of mannitol sugar which is bacteria pathogen as shown in the table (1) which shows the results of biochemical tests of bacteria. S. aureus bacteria can live in anaerobic conditions (Hoffman, 2012).

Table 1:-Results of morphological and biochemical tests for S. aureus Identification

\begin{tabular}{|l|l|l|}
\hline No. & Type of test & Results \\
\hline $\mathbf{1}$ & Haemolysis & $\beta$ - Hymatolysis \\
\hline $\mathbf{2}$ & Plasma coagulation & + ev \\
\hline $\mathbf{3}$ & Catalase & $+\mathrm{ev}$ \\
\hline $\mathbf{4}$ & Gram stain & + ev \\
\hline $\mathbf{5}$ & Color of colony & Orange \\
\hline $\mathbf{6}$ & Shape of colony & Large, smooth, circular \& convex \\
\hline $\mathbf{7}$ & Motility & $-\mathrm{ev}$ \\
\hline $\mathbf{8}$ & Shape & cocci \\
\hline $\mathbf{9}$ & Spore forming & $-\mathrm{ev}$ \\
\hline $\mathbf{1 0}$ & Voges Proskauer VP. & $+\mathrm{ev}$ \\
\hline $\mathbf{1 1}$ & Glucose fermentation & $+\mathrm{ev}$ \\
\hline $\mathbf{1 2}$ & Starch fermentation & $+\mathrm{ev}$ \\
\hline $\mathbf{1 3}$ & Mannitol fermentation & $+\mathrm{ev}$ \\
\hline
\end{tabular}

This species of bacteria can cause skin infections such as abscesses, respiratory infections such as sinusitis and food poisoning. S. aureus has the ability to produce super-antigen which can cause the toxic shock syndrome after ingestion contaminated food with high number of $S$. aureus, also considered as a cause of meningitis, osteoarthritis, endocarditis, bacteremia of Blood, and sepsis (Hoffman, 2012; Valyal et al., 2017), it's still one of five most common causes of infections acquired in hospitals and often in hospitals are the cause of postoperative wound infections. 500,000 patients at the United States of America are suffering from Staphylococcus sp. infections mainly with Staphylococcus aureus (Sanford, 2012), approximately 50,000 deaths annually in the United States associated with species of $S$. aureus.

\section{Bacillus cereus}

Results of microscopic examination tests after chromium pigmentation showed bacteria measurements were 4 microns and 1.5 microns in length, which are positive for chromium dye and appeared on nourishing broth in relatively large and diffused colonies. The appearance of B. cereus color was creamy and had the ability to form blackboards (Asaeda et al., 2005). The test of catalase result was positive also for glucose, starch, and positive Voges Proskauer examination. B. cereus worked clearly on clotting of plasma as a satisfactory bacteria. When $B$. cereus cultured in the center of blood agars were analyzed blood type of beta-Hymatolysis, also developed colonies surrounded by a transparent halo signify the decomposition Full blood also when grown on the nourishing gravy on sodium salt, grown well as shown in table 2 . 
Table 2:-Results of morphological and biochemical tests for B. cereus Identification

\begin{tabular}{|l|l|l|}
\hline No. & Type of test & Results \\
\hline $\mathbf{1}$ & Haemolysis & - Hymatolysis \\
\hline $\mathbf{2}$ & Plasma coagulation & $+\mathrm{ev}$ \\
\hline $\mathbf{3}$ & Catalase & $+\mathrm{ev}$ \\
\hline $\mathbf{4}$ & Gram stain & $+\mathrm{ev}$ \\
\hline $\mathbf{5}$ & Color of colony & White \\
\hline $\mathbf{6}$ & Shape of colony & Large, waxy and branched \\
\hline $\mathbf{7}$ & Motility & -ev \\
\hline $\mathbf{8}$ & Shape & Rod shape \\
\hline $\mathbf{9}$ & Spore forming & + ev \\
& & Subterminal endospore \\
\hline $\mathbf{1 0}$ & Voges Proskauer VP. & + ev \\
\hline $\mathbf{1 1}$ & Glucose fermentation & $+\mathrm{ev}$ \\
\hline $\mathbf{1 2}$ & Starch fermentation & $+\mathrm{ev}$ \\
\hline
\end{tabular}

B. cereus bacteria can cause diarrhea and vomiting as a result due to food poisoning syndrome. It can cause chronic dermatitis and corneal inflammation (Guinebretière et al., 2013). This type of bacteria has the ability to form blackboards and cannot be easily killed by alcohol, in fact, Distilled alcohol and smears that have soaked in alcohol and bandages, these colonies are in sufficient numbers to cause infection (Kocur and Martinec, 1959; Frankland and Frankland, 1887)

\section{Enterococcus faecal}

The result of Microscopic examination showed the post-chromosome that the spherical bacteria took the form of chains. Individually E. faecal is positive for the chromium dye and appeared on the nourishing broth in colored white colonies of the relatively large diameter of 2-4 mm. Examination of ability to form blackboards, they were neither spores nor non-motile, Catalase, and starch for glucose and starch, Voges Proskauer and not on plasma coagulation. When cultured on blood agar, alpha-Hymatolysis was detected and grew as green colonies indicative of partial blood decomposition also when cultured on nutrient broth which contain $\mathrm{NaCl}$ grew well and clear. Table (3) shows the morphological and biochemical tests of E. faecal bacteria.

Table 3:-Results of morphological and biochemical tests for E. faecal Identification

\begin{tabular}{|l|l|l|}
\hline No. & Type of test & Results \\
\hline $\mathbf{1}$ & Haemolysis & - Hymatolysis \\
\hline $\mathbf{2}$ & Plasma coagulation & $-\mathrm{ev}$ \\
\hline $\mathbf{3}$ & Catalase & $+\mathrm{ev}$ \\
\hline $\mathbf{4}$ & Gram stain & $+\mathrm{ev}$ \\
\hline $\mathbf{5}$ & Color of colony & White \\
\hline $\mathbf{6}$ & Shape of colony & Large, smooth, circular \& convex \\
\hline $\mathbf{7}$ & Motility & -ev \\
\hline $\mathbf{8}$ & Shape & Cocci \\
\hline $\mathbf{9}$ & Spore forming & $-\mathrm{ev}$ \\
\hline $\mathbf{1 0}$ & Voges Proskauer VP. & $+\mathrm{ev}$ \\
\hline $\mathbf{1 1}$ & Glucose fermentation & $+\mathrm{ev}$ \\
\hline $\mathbf{1 2}$ & Starch fermentation & $+\mathrm{ev}$ \\
\hline
\end{tabular}

E. faecal is anaerobic, and selective living bacteria, with capable of cellular respiration in both environments which rich oxygen and poor (Sandle, 2014). Although it isn't able to form blackboards, it has the ability to live in variable environmental at a range of temperatures $\left(10-45^{\circ} \mathrm{C}\right), \mathrm{pH}(4.5$ to 10.0$)$ and high sodium chloride concentrations (Ingrun et al., 2006), which indicates their high ability to live in harsh environmental conditions. E. faecal bacteria belong to the group of bacteria producing lactic acid (LAB) (Sandle, 2014; Bories et al., 2008). Clinical infection is caused by E. faecal is urinary tract infections, bacteremia, bacterial endocarditis and meningitis (Budzik and Schneewind, 2006). Sensitive strains of these bacteria can be treated by Ampicillin, Penicillin, and Vancomycin (Brown et al., 2006; Busani et al., 2004). From a medical point of view, there is an important feature of this type as it has a high level of resistance to essential antibiotics. Some intestinal bacteria have the ability to fold antibiotic 
(Penicillin, Cephalosporin, Carbapenimate), as well as many aminoglycosides (Bories et al., 2008; Wade Road, 1982). At the past two decades, E. faecal infection has been reported in patients at hospitals of USA. The epidemic In 2005 Singapore managed to stop the epidemic, and response rates were about 70\% (Alksne and Projan, 2000).

\section{Conclusion:-}

The results of this study showed the equipments in hospitals, especially the devices that are in direct contact with liquid or blood samples and blood withdrawn from the patients and patients are susceptible to pollution, which causes inflammation of patients in the hospital and the use of these devices, including blood storage refrigerators that may be contaminated as a result of accidental spills or storage for a period along more than 7 days, the recommended period with the lack of sanitary conditions (blood transfusion tubes and blood bags) or the blood of the donor person is contaminated with an infectious disease so that the bacteria multiply pathogenic in the blood which is a very ideal media for growth of these types of pathogens (Berk and Verghese, 1989)

The most important types of bacteria that cause infections or hospital infection is the bacterium $S$. aureus, which causes inflammation of the tonsils, pharynx and disease herpes skin and bacteria Pseudomonas aeruginosa responsible about pneumonia and Escherichia coli can cause urinary tract infections and is clinical infections caused via $E$. faecal infections, urinary tract that, and bacteremia and inflammation Bacteria and meningitis Bacillus cereus bacteria were found in food, blankets, and corals and were isolated from intravenous fluid also causing endemic bacteremia (Andrup and Andersen, 1999). In general, patients and all workers at hospitals, as well as furniture's, tools and medical devices which used in treatments and exercises, can be considered a potential source of transfer of microbial species and a catalyst of rapid movement between patients and hospital staffs if the highest hygiene, disinfectant and sterilization conditions are not maintained within the hospital and require strong types of antibiotics.

\section{Recommendations:-}

1. In the case of disposing medical devices, this must be done by returning the equipment to the equipped company for the necessary procedures.

2. Sterilization of laboratories and hospitals continuously periodically and taking preventive measures when dealing with refrigerators, especially refrigerators of blood preservation.

3. The medical devices shall be consumed after the end of their life according to the recommendations of the manufacturer or the failure is not maintenance and must be treated with any consumer device with caution and is a pollutant and a danger to the health of patients who are in hospital and staff in constant contact with such devices (Bearman and Wenzel, 2005)

\section{References:-}

1. Carson, J.L., Stanworth, S.J., Roubinian, N., Fergusson, D.A., Triulzi, D., Doree, C., Hebert, P. C., 2016. Transfusion thresholds and other strategies for guiding. allogeneic red blood cell transfusion. The Cochrane Database of Systematic Reviews. Cochrane library. Wiley 1-24.

2. Ibrahim, I.H., 2013. Pathogenic bacteria, Chapter 5. The genus of Staphylococcus sp., first edition 50-61

3. Masalha, M., Borovok, I., Schreiber, R., Aharonowitz, Y., Cohen, G., 2001. Analysis of transcription of the Staphylococcus aureus aerobic class Ib and anaerobic class III ribonucleotide reductase genes in response to oxygen 183(24),7260-72.

4. Tong, S.Y., Davis J.S., Eichenberger, E,. Holland, T.L,. Fowler, V.G., 2015. "Staphylococcus aureus infections: epidemiology, pathophysiology, clinical manifestations, and management". Clinical Microbiology Reviews 28

5. Wade Road., 1982. Agents and Main Distributors 3th ed. Oxoid 88-100.

6. Senok, A.C., Verstraelen, H., Temmerman, M., Botta, G A., Senok, A.C., 2009. Probiotics for the treatment of bacterial vaginosis. The Cochrane Database of Systematic Reviews. Cochrane library. Wiley 1-24.

7. Hoffman, B., 2012. Williams gynecology, 2nd edition. New York: McGraw-Hill Medical. 65

8. Valyal, B., Das, S.K.R., Kavya, T., Vidyasagar, V., Begum, R., 2017. Antibiotic sensitivity and resistance pattern in orthopedic infectious cases of a tertiary care teaching hospital. Pharmacology. 7 (4), 24- 29

9. Sanford, C.A., Jong, E.C., 2008. The Travel and Tropical Medicine Manual. Elsevier Health Sciences 469

10. Asaeda, G., Caicedo, G., Swanson, C., 2005. Fried Rice Syndrome. Journal of Emergency Medical Services. 30 (12), 30-32.

11. Guinebretière, M.H., Auger, S., Galleron, N., Contzen, M., De Sarrau, B., De Buyser, M.L., Lamberet, G., Fagerlund, A., Granum, Per E., Lereclus, D., De Vos, P., Nguyen-The, C., Sorokin., A., 2013. Bacillus 
cytotoxicus sp. nov. is a novel thermotolerant species of the Bacillus cereus Group occasionally associated with food poisoning. International Journal of Systematic and Evolutionary Microbiology. 63 (1), 31-40.

12. Frankland, G.C., Frankland, P. F., 1887. Studies on Some New Micro-Organisms Obtained from Air. Philosophical Transactions of the Royal Society B: Biological Sciences. 178, 257-287.

13. Kocur, M., Martinec, T., 1959. The Taxonomic Study of Sarcina Aurantiaca Fluegge. International Bulletin of Bacteriological Nomenclature and Taxonomy 9 (4), 165-168

14. Sandle, T., 2014. The Risk of Bacillus cereus to Pharmaceutical Manufacturing. American Pharmaceutical Review (Paper). 17 (6): 56.

15. Alseth, I., Rognes, T., Lindbäck, T., Solberg, I., Robertsen, K., Kristiansen, K.I., Mainieri, D., Lillehagen, L., Kolstø, A-B., Bjørås, M., 2006. A new protein superfamily includes two novel 3-methyladenine DNA glycosylases Bacillus cereus, AlkC and AlkD. Molecular Microbiology 59

16. Bories, G., Brantom, P., de Barberà, Joaquim Brufau; et al. (2008). Safety and efficacy of the product Toyocerin (Bacillus cereus var. toyoi) as feed additive for rabbit breeding does. EFSA Journal. Scientific Opinion of the Panel on Additives and Products or Substances used in Animal Feed. European Food Safety Authority. 913: 1-13

17. Alksne, LE., Projan, SJ. (2000). Bacterial virulence as a target for antimicrobial chemotherapy. Curr Opin Biotechnol. 11: 625-636.

18. Andrup, L., Andersen, K. (1999). A comparison of the kinetics of plasmid transfer in the conjugation systems encoded by the F plasmid from Escherichia coli and plasmid pCF10 from Enterococcus faecalis. Microbiology 145, 2001-2009.

19. Bearman, G ML., Wenzel, RP. (2005). Bacteraemias: a leading cause of death. Arch Med Res 36: 646-659.

20. Billström, H., Lund, B., Sullivan, $\mathrm{A}^{\circ}$. \& Nord, C. E. (2008). Virulence and antimicrobial resistance in clinical Enterococcus faecium. Int J Antimicrob Agents 32: 374-377.

21. Brown, D. F. J., Brown, N. M., Cookson, B. D., Duckworth, G., Farrington, M., French, G. L., King, L., Lewis, D., Livermore, D. M. \& other authors (2006). National glycopeptide-resistant enterococcal bacteremia surveillance Working Group report to the Department of Health. J. Hosp Infect 62 (Suppl. 1), 1-27.

22. Budzik, J M., Schneewind, O. (2006). Pili prove pertinent to enterococcal endocarditis. J Clin Invest 116, 25822584.

23. Busani, L., Del Grosso, M., Paladini, C., Graziani, C., Pantosti, A., Biavasco, F., Caprioli, A. (2004). Antimicrobial susceptibility of vancomycin-susceptible and -resistant enterococci isolated in Italy from raw meat products, farm animals, and human infections. Int J Food Microbiol. 97

24. MOH, (2013).Standard Operation Procedure for Facility and Equipment Maintenance Maintenance Management in primary Health Care Centers.P18.

25. Berk SL, Verghese A. (1989) Emerging pathogens in nosocomial pneumonia. Eur J Clin Microbiol Infect Dis. 8(1):11-14 